\title{
Development of Social Roles in Elicited and Spontaneous Behavior During the Preschool Years
}

\author{
Malcolm W. Watson \\ Brandeis University
}

\author{
Kurt W. Fischer \\ University of Denver
}

\begin{abstract}
In two experiments, children between $1 \frac{1 / 2}{2}$ and $7 \frac{1}{2}$ years of age were tested on a predicted, eight-step sequence of the development of social roles. Performance on this sequence was related to two measures of more spontaneous behavior. Nearly all children fit the predicted sequence perfectly. By 2 years of age, most children could make a doll act as an independent agent. The majority of 3-yearolds could make a doll carry out several behaviors fitting the role of doctor. At age 4 or 5, most children developed the capacity to show a social role, making a doctor doll interact with a patient doll. The intersection of social roles for two agents appeared at about age 6: A man doll could be both doctor and father to a patient who was also his daughter. In their spontaneous behavior, early preschoolers almost always showed the highest step that they were capable of, but beginning with the step for social roles, late preschoolers seldom showed their highest step.
\end{abstract}

For children to act and feel socially competent, they need to understand roles such as mother, father, doctor, and patient. Despite the importance of these social roles in the child's life, the development of social roles in the preschool years is, at best, only vaguely understood. The several previous studies of social-role development have concluded that children do not really understand social roles until 7 or 8 years of age (Bigner, 1974; Chambers \& Tavuchis, 1976; Elkind, 1962; Emmerich, 1959, 1961; Greenfield \& Childs, 1977; Sigel, Saltz, \& Ros-

Experiment 2 was part of the first author's doctoral dissertation at the University of Denver. The research was supported by a predoctoral research fellowship to the first author from the National Institute of Mental Health, 1F31 MH05321-02; by a student research grant to the first author from the Grant Foundation; and by a research grant to the second author from the Spencer Foundation.

The authors wish to thank Daniel Bullock, Joseph Campos, Paul Corbitt, Susan Harter, Sandra Pipp, and Phillip Shaver for invaluable assistance and suggestions in completing these studies. Special thanks to Ralph J. Roberts, Jr., for collecting the data in Experiment 1 and helping with many other parts of the research.

Requests for reprints should be sent to Malcolm W. Watson, Department of Psychology, Brandeis University, Waltham, Massachusetts 02154 . kind, 1967). Thus they have uniformly supported Piaget's (1928) early conclusion that the understanding of social roles is a relatively late development.

There is reason to believe, however, that this research underestimates the preschool child's understanding of social roles. Several investigators have described behaviors or capacities in preschool children that imply some understanding of social roles (El'Konin, 1971; Piaget, 1951). Recent research on other skills has shown that many abilities that were thought to first emerge at age 7 or 8 are in fact present in some form several years earlier (Gelman, 1978). And at least one theory of cognitive development, called skill theory (Fischer, in press), predicts that even in the early preschool years children should be able to understand social roles in concrete situations. To demonstrate such skills in young preschool children, it is necessary to use a task that is simple and concrete and does not overload the preschool child with complicated instructions or a need to explain the roles verbally.

In addition, the sequence of role-concept development needs to be determined. With specification of a sequence, many controversies about age of acquisition can be 
resolved (Rubin \& Pepler, in press). Skill theory provides mechanisms for predicting such a sequence.

According to this theory, children's skills develop through a set of hierarchically organized levels, each of which first emerges at a certain average age within a given population. Each level is described in terms of a skill structure, an organization of actions or representations that a child can control. In addition, several transformation rules specify how skills at a given level can be made more complex. In the present studies, the rule used most often is compounding, in which an additional component is added to a skill at a given level; for example, a skill comprised of two actions is expanded to subsume three actions.

In the present research, we used skill theory to predict a sequence for the development of social roles in pretend play for the ages from approximately 1 to 7 years (see Table 1). The sequence contains eight steps, but there is nothing special about this number. The number and nature of the steps that children show will vary with the contexts to which the children are exposed.

Before determining the actual steps that we would assess, we observed several dozen preschool children in pretend-play situations. The specific steps that we tested involved pretend stories similar to ones that appeared in those situations.

According to skill theory, children between 1 and 7 years of age develop through four levels. At about 1 year of age, the level of sensory-motor systems emerges, in which children can coordinate several aspects of two or more actions into a single skill. In the first step in the sequence to be tested, self as agent, children coordinate actions such as looking, holding, and touching with the lips so that they can, for example, pretend to drink from a cup.

The next two steps involve the development of skills for making agents, such as dolls, act independently of the child. Both of these steps require the second of the four cognitive levels - single representationsthat typically emerges at about age 2 . In a simple type of representation, children coordinate two sensory-motor systems into a single skill. Thus, at Step 2, active other agent, a system for manipulating a doll is coordinated with a system for some other behavior, such as drinking or walking, with the result that the child can make the doll drink or walk (Fischer \& Corrigan, in press; Watson \& Fischer, 1977). The third step, active substitute agent, is at the same cognitive level and is predicted by the transformation rule of substitution, by which a block can be substituted for the doll in Step 2 .

Such skills for making dolls and blocks act as independent agents would seem to be precursors of skills for social roles, since a role involves multiple behaviors of an independent agent. The first two steps are also suggested by research on children's spontaneous pretend play (Dasen, Inhelder, Lavallée, \& Retschitzki, 1978; Watson $\&$ Fischer, 1977).

Step 4, behavioral role, is predicted by the transformation rule of compounding. The simple representation in Steps 2 and 3 can be expanded to include additional behaviors, so that the child can make the doll carry out two or more behaviors coordinated around a specific role, such as mother or doctor.

The fifth step represents the emergence of the first skills that fit the standard definition of a role. In social psychology and sociology, the cluster of behaviors defining a social role is determined by the relationship of that role to another complementary role (Mead, 1934). For example, the role of medical doctor is related to the complementary role of patient, with the person in each role expecting certain behaviors of the person in the other role. Step 4 involves a role by itself. A role related to its complement first develops at Step 5, social role. This relation of a role to its complement requires the next cognitive level, representational mappings, in which two or more representations are related in a single skill. This level first emerges at about age 4, according to previous research in other domains (Fischer, in press).

In the several years after children first demonstrate specific social roles, they will develop the ability to perform the kinds of role tasks investigated in most previous studies (e.g., Sigel et al., 1967). By compounding more than two roles into a com- 
plex. representational mapping, they can relate a social role to several complements, as in Step 6, social role with three agents. At about 6 years of age, they will become capable of the next cognitive level, representational systems, in which several aspects of two or more representations are coordinated. They will therefore be able to

Table 1

Predicted Developmental Sequence of Social Role Playing

\begin{tabular}{|c|c|c|}
\hline Cognitive level/step & Role-playing skill & Modeled behaviors \\
\hline \multicolumn{3}{|l|}{ Sensory-motor systems } \\
\hline 1 & $\begin{array}{l}\text { Self as agent: A person pretends to } \\
\text { carry out one or more behaviors, } \\
\text { not necessarily fitting a social role. }\end{array}$ & $\begin{array}{l}\text { Experimenter pretends to drink from } \\
\text { an empty cup. }\end{array}$ \\
\hline \multicolumn{3}{|l|}{ Single representations } \\
\hline 2 & $\begin{array}{l}\text { Active other agent: An agent performs } \\
\text { one or more behaviors, not } \\
\text { necessarily fitting a social role. }\end{array}$ & $\begin{array}{l}\text { Experimenter pretends that a doll is } \\
\text { talking, walking, eating, and } \\
\text { washing, as if it were actually } \\
\text { carrying out the actions itself. }\end{array}$ \\
\hline 3 & $\begin{array}{l}\text { Active substitute agent: An object } \\
\text { substituting for an agent performs } \\
\text { one or more behaviors, not } \\
\text { necessarily fitting a social role. }\end{array}$ & $\begin{array}{l}\text { Experimenter pretends that a block is } \\
\text { walking, eating, talking, and going } \\
\text { to sleep, as if it were a person or } \\
\text { a doll. }\end{array}$ \\
\hline 4 & $\begin{array}{l}\text { Behavioral role: An agent performs } \\
\text { several behaviors fitting a social } \\
\text { role (in this case, doctor). }\end{array}$ & $\begin{array}{l}\text { Experimenter pretends that a doctor- } \\
\text { doll uses a thermometer and an } \\
\text { otolargyngoscope on another doll. }\end{array}$ \\
\hline \multicolumn{3}{|l|}{ Representational mappings } \\
\hline 5 & $\begin{array}{l}\text { Social role: One agent behaving } \\
\text { according to one social role (doctor) } \\
\text { relates to a second agent behaving } \\
\text { according to a complementary } \\
\text { social role (patient). }\end{array}$ & $\begin{array}{l}\text { Experimenter pretends that a patient } \\
\text { doll is sick and a doctor doll } \\
\text { examines her and gives her some } \\
\text { medicine. The patient doll makes } \\
\text { appropriate responses during the } \\
\text { examination. }\end{array}$ \\
\hline 6 & $\begin{array}{l}\text { Social role with three agents: Two } \\
\text { complementary roles (patient and } \\
\text { nurse), instead of just one, are } \\
\text { simultaneously related to the first } \\
\text { role (doctor). }\end{array}$ & $\begin{array}{l}\text { Experimenter pretends that a doctor } \\
\text { doll examines a sick patient doll and } \\
\text { is aided by a nurse doll. Both } \\
\text { patient and nurse respond } \\
\text { appropriately. }\end{array}$ \\
\hline \multicolumn{3}{|l|}{ Representational systems } \\
\hline 7 & $\begin{array}{l}\text { Intersection of social roles for two } \\
\text { agents: Two separate, agent- } \\
\text { complement role relations are } \\
\text { coordinated so that one agent is in } \\
\text { two roles simultaneously and relates } \\
\text { to another agent in two comple- } \\
\text { mentary roles (doctor-father with } \\
\text { patient-daughter). }\end{array}$ & $\begin{array}{l}\text { Experimenter pretends that a doctor } \\
\text { doll examines a sick patient doll } \\
\text { and also acts as a father to the } \\
\text { patient, who is his daughter. The } \\
\text { patient doll responds appropriately } \\
\text { as both patient and daughter. }\end{array}$ \\
\hline 8 & $\begin{array}{l}\text { Intersection of social roles for three } \\
\text { agents: Three separate agent- } \\
\text { complement role relations are } \\
\text { coordinated so that one agent in two } \\
\text { or three roles simultaneously } \\
\text { relates to two other agents each in } \\
\text { the relevant complementary roles } \\
\text { (doctor-father-husband with } \\
\text { patient-daughter and mother of } \\
\text { patient-wife). }\end{array}$ & $\begin{array}{l}\text { Experimenter pretends that one doll } \\
\text { is a doctor, father, and husband } \\
\text { relating to two other dolls. The } \\
\text { second doll is a sick patient and } \\
\text { the first doll's daughter. The third } \\
\text { doll is the patient's mother and the } \\
\text { first doll's wife. }\end{array}$ \\
\hline
\end{tabular}

Note. The stories and exact scoring criteria are available from the authors on request. 
build skills for relating several intersecting social roles for the same agent, as in Steps 7 and 8 . Such role intersection seems to be a genuine concern of many preschool children, as illustrated by a question one 6-yearold asked of his father: "Daddy, when you finish school and become a psychologist, will you still be my daddy?" Step 8 occurs after Step 7 because it requires a compounded representational system.

To assess this predicted sequence, we chose to use a modeling-and-imitation technique employed in some previous research. Other studies have concluded that in pretending, children do not blindly mimic a model but demonstrate only those aspects that they can understand or assimilate (Gottlieb, 1973; Harnick, 1978; McCall, Parke \& Kavanaugh, 1977; Scollon, 1976; Slobin \& Welsh, 1973). In fact, the modeled actions seem to act as general facilitators of pretending (Watson \& Fischer, 1977) as long as the modeling and pretending occur in a context in which the behaviors are appropriate for the child (see Bloom, Rocissano, \& Hood, 1976). Also, a similar modeling procedure is commonly used in play therapy with preschool children: The therapist acts out or explains a story or theme of some kind, and the child frequently picks up the story or theme and incorporates it into his or her play (e.g., Harter, 1977).

We introduced several modifications of the typical modeling-and-imitation procedure, however. First, each developmental step was independently assessed by a separate story that was devised expressly to test that step: The children watched the experimenter model each story and then tried to do it themselves. With this strong form of scalogram analysis, we could directly test the developmental sequence with a cross-sectional design.

Second, we tried to directly assess the relation between behavior under this immediate-elicited-imitation procedure and behavior under a more spontaneous condition like that used in Watson and Fischer (1977). Most studies of development in play assess only the child's spontaneous preferences and must assume that they are observing the child's highest capabilities. We were able to compare capabilities under two conditions. After the elicited-imitation assessment, each child was left to play alone with the toys. The child's behavior under this free-play condition was undoubtedly affected by the prior occurrence of the elicited condition, but the free-play condition did give some indication of what the children preferred to do when their behavior was not constrained to immediate imitation. In two previous studies using only a procedure similar to the free-play condition (Harnick, 1978; Watson \& Fischer, 1977), the pattern of steps that 1- and 2-year-olds spontaneously performed showed not only the acquisition of the steps in a developmental sequence but also the deletion or omission of steps in the same order as the steps had been acquired (i.e., first in, first out). A reasonable extrapolation from those studies is that in the elicited-assessment condition children will correctly perform all steps up to the highest that they are capable of, but in the free-play condition they will show a systematic combination of acquisition and omission similar to that in the previous study.

The hypotheses tested, then, were: (a) In the elicited-assessment condition, preschool children will demonstrate the developmental sequence for social roles described in Table 1. (b) The first steps will be achieved by early preschool childrenself as agent by about $1 \frac{1 / 2}{2}$ years of age, active other agent by about 2 years. The first demonstration of a social role (Step 5) will emerge at about 4 years of age, and the first intersection of roles (Step 7) will appear at about age 6 . (c) In the free-play condition, children will show the same developmental sequence as in the elicited-assessment condition, but they will not show all the earlier steps that they are capable of. The omission of earlier steps may follow the same sequence as the acquisition of steps.

Two experiments were completed to test these hypotheses.

\section{Experiment 1}

\section{Method}

\section{Subjects}

Subjects were 40 normal, white, middle-class children whose parents had volunteered to have them 
participate in the study. Four age groups were tested, with respective mean ages of 1 year 6 months (all the same age), 2 years (range $=2$ years to 2 years 1 month), 3 years (all were 3 ), and 4 years 3 months (range $=3$ years 11 months to 4 years 3 months). There were 10 children in each group, 5 of each sex. All children brought to the laboratory completed the study except 12 -year-old and 14 -year-old. These 2 children would not cooperate in performing the elicitedassessment tasks.

\section{Facilities and Apparatus}

Testing took place in a carpeted playroom, furnished with curtains, pictures on the walls, a chair for the mother, and a child's chair and round table. A microphone hung from the center of the ceiling.

Toys consisted of a set of two Milton-Bradley rigid cardboard dolls in plastic stands that represented realistic stereotypes of a male medical doctor and a female child (patient). The doctor was $20 \mathrm{~cm}$ high and the patient $12 \mathrm{~cm}$ high. Also used were a set of wooden doll furniture and a toy doctor's kit consisting of a container, syringe, thermometer, medicine bottle, otolaryngoscope, and sponge.

Each child's behavior and vocalizations throughout the session were recorded on videotape from an adjoining observation room. The camera was situated behind a filming window that was covered with black cloth. The camera was virtually invisible to the child.

\section{Procedure}

All children were tested in two conditions, elicited assessment and free play. The two conditions were always administered in the same order because the occurrence of a high frequency of pretending is facilitated by adult modeling (Watson \& Fischer, 1977). Also, we wanted to maximize the chances that the children would show the same steps in the two conditions.

After a mother and child entered the playroom and sat down, the experimenter explained to the child that he wanted to see how children played and acted out stories and that together they would play a game, but first he had to get something ready in another room, and that the child could go ahead and play with the toys while the experimenter was gone.

Familiarization. The experimenter left the room, and the child was allowed to play for 3-4 min to become familar with the setting and objects.

Elicited assessment. The experimenter reentered the room and told the child that they would use the dolls to act out some stories and that he wanted to see how good an actor the child was. The experimenter asked the child to watch how he acted out each story and then take a turn acting out his or her own story, using the same dolls and ideas that the experimenter used. The experimentor told the child that if he or she did a good job, he would provide a surprise toy afterward; however, he also told the child that the story need not be exactly like the experimenter's. The presentation of the modeled stories, each followed by an imitative story from the child, lasted approximately 15 minutes. A warm-up task was presented before the experimental tasks: the mother doll was made to eat and sleep as an active agent.

Then, to test each of the steps, similar but distinct stories were modeled, one representing each step in the sequence. In this experiment, Steps 1-5 were tested (see Table 1). In the story for the first step, the experimenter himself pretended to drink from a cup. In the other stories, he made one or two dolls act and talk. If the child did nothing after the experimenter demonstrated a story, then the experimenter showed it again. Each story took from 30 to $50 \mathrm{sec}$ to model, and the ordering of the stories by length was not the same as the predicted developmental sequence or the order of testing. The duration of the children's stories after each modeled story ranged from 20 to $180 \mathrm{sec}$.

The stories were presented in a scrambled order so that neither practice nor fatigue effects could artifactually produce an apparent scalable sequence; the order of the tasks, designated by step number, was $4,2,1,5,3$.

Free-play condition. After the modeling and elicited imitation were completed, the experimenter said that he had to leave for a short time but that the child could continue to play. The experimenter suggested that the child act out some more stories on his or her own. The child was then left to play alone for 6 minutes. This behavior was later scored in terms of the steps in the developmental sequence. Thus it provided a measure of what might be called "imitative pretend play" - pretend behavior that reflects the stories modeled by the experimenter but is not rigidly constrained by them. This procedure is similar to that used in the previous study by Watson and Fischer (1977). The experimenter then returned to the playroom and debriefed the mother and child.

\section{Scoring and Interobserver Reliability}

The experimenter scored each child's performance from the videotapes by using established criteria to rate each of the child's stories for the role-playing step demonstrated. In the elicited assessment, exact imitation of the experimenter's story was not required and was seldom shown. To pass the task for a given step, the child had only to meet minimum criteria of agent use and role relations for showing that particular step, as outlined in the descriptions of the skills for each step in Table 1; thus the child could pass a step by acting out a story in which the actions were not at all like those of the experimenter so long as they fit the general criteria for the step.

A second observer, blind to the hypothesized sequence, the exact age of the children, and the other observer's ratings, scored the performances of one randomly selected child of each sex from each age group. For these eight children, the interrater reliability for highest step passed in the elicited-assessment condition was perfect $(r=1.00)$. Across all steps in the elicited assessment, the mean percentage of perfect agreement was 97.5.

In the free-play condition, all children spent much of their time playing with the dolls, acting out a median and mode of seven stories per child. Each episode 
that they acted out was scored for the step that it showed. Scoring criteria were the same as those for the elicited-assessment condition. The reliability of the two highest step passed was nearly perfect $(r=.95)$; for all steps shown, the two observers agreed completely $95 \%$ of the time.

\section{Results}

The hypothesized sequence was strongly supported, but there were important differences between the two conditions.

\section{Sequence}

To test whether the obtained task profiles for individual children indicated a scalable developmental sequence, we used scalogram analysis, in particular Green's (1956) tests for reproducibility and consistency.

The sequence was tested separately in each condition. For the elicited-assessment condition, the sequence was strongly supported. Green's (1956) index of consistency (I) was .87 , indicating a highly scalable sequence. As shown in Table 2, 38 of 40 children fit the predicted profiles perfectly, and the other 2 each skipped only one step.

One of the five steps did not scale strongly, however. Step 3, active substitute agent, proved to show almost the same profiles as Step 2, active other agent. Only two children passed Step 2 without passing Step 3; one child passed Step 3 without passing Step 2.

For the free-play condition, however, the sequence did not prove to be scalable $(I=$
.18). Even when Step 3 was combined with Step 2, the sequence was still not scalable $(I=.29)$. Also, when children omitted steps, their omissions did not follow the order of acquisition.

\section{Highest Step}

Although the sequence did not scale in the free-play condition, there was evidence that the children's behavior in free play did reflect their ability as assessed in the elicited-assessment condition. In the freeplay condition, most children (35 of 40) showed the highest step that they were capable of according to the elicited assessment, and none showed a higher step. With Steps 2 and 3 combined, the correlation between highest step in the two conditions was nearly perfect, $r(38)=.94, p<.001$. Likewise, the correlation of each measure with age was high: for elicited assessment, $r(38)=.86, p<.001$, and for free play, $r(38)=.85, p<.001$. When age was partialed out, the correlation between the two conditions was still substantial, $r(23)=$ $.77, p<.001$.

In an analysis of variance with age and sex as between-subjects factors and condition (assessment and free play) as a withinsubjects factor, there was a significant age effect, $F(3,32)=50.7, p<.001$. On a 4 point scale, the mean highest steps were $1.00,1.95,2.85$, and 3.40 in order of increasing age. By the Tukey posthoc test, the first three age groups were all significantly different from each other, but the third

Table 2

Distribution of Children Showing Task Profiles in Experiment I

\begin{tabular}{|c|c|c|c|c|c|c|c|}
\hline \multirow{2}{*}{$\begin{array}{l}\text { Developmental } \\
\text { step of profiles }\end{array}$} & \multicolumn{5}{|c|}{ Role-playing task } & \multirow[b]{2}{*}{$n$} & \multirow[b]{2}{*}{$M$ age } \\
\hline & 1 & 2 & 3 & 4 & 5 & & \\
\hline 0 & - & - & - & - & - & 1 & 1 year 6 months \\
\hline 1 & + & - & - & - & - & 7 & 1 year 7 months \\
\hline 2 & + & + & - & - & 一 & 2 & 1 year 10 months \\
\hline 3 & + & + & + & - & - & 12 & 2 years 4 months \\
\hline 4 & + & + & + & + & - & 10 & 3 years 5 months \\
\hline 5 & + & + & + & + & + & 6 & 3 years 11 months \\
\hline Nonscalable profiles & + & - & + & - & - & 1 & 2 years \\
\hline Total & + & + & + & - & + & $\begin{array}{r}1 \\
40\end{array}$ & 4 years 3 months \\
\hline
\end{tabular}

Note. Occurrence of the designated type of role playing is indicated by + . 
and fourth groups did not differ significantly. There were no other main effects or interactions.

Despite the absence of an Age $\times$ Condition interaction, more fine-grained analysis did suggest an age change. Of the five children who did not play at their highest step in free play, four had Step 5 as their highest step in the elicited assessment; three other children with Step 5 as their highest step did show it in their play.

\section{Experiment 2}

The second experiment assessed the rest of the predicted sequence and retested several of the steps assessed in Experiment 1. In addition to assessing the sequence, it provided a test of the possible Age $\times$ Condition interaction in Experiment 1: If the findings for Step 5 in the free-play condition indicated a reliable change that was a function of age or cognitive level, then a similar pattern of results should occur not only for Step 5 but for all later steps as well. Also, to test the generality of the findings, we introduced another condition: After the free-play session, children were asked to act out the best story they could.

\section{Method}

\section{Subjects}

Subjects were 68 normal, white, middle-class children whose parents had volunteered to have them participate in the study. There were five age groups, with respective mean ages of 1 year 6 months (all the same age), 3 years (range $=2$ years 11 months to 3 years 3 months), 4 years 6 months (range $=4$ years 5 months to 4 years 11 months), 6 years (range $=$ 5 years 10 months to 6 years 3 months), and 7 years 6 months (range $=7$ years 6 months to 7 years 7 months). In each of the middle three age groups, there were 20 children (10 of each sex) for a total of 60 children. Only 4 children ( 2 of each sex) were tested in each of the groups aged 1 year 6 months and 7 years 6 months because these children were added to obtain data for the extreme steps in the scalogram analysis only.

All children brought to the laboratory completed the study except three 3-year-old boys and two 3-year-old girls. These five children were shy and did not carry out the elicited-assessment stories.

\section{Procedure}

The procedure was the same as in Experiment 1 in most respects. The experimenter was a different adult male experienced with preschool children (the first author). In addition to the doctor and child dolls, two additional dolls of the same brand and style were added for the later steps - a woman nurse and a woman who served as the mother of the patient. Steps 2, 4, 5, 6, 7, and 8 were tested.

To assess for order defects, we presented the elicitedassessment tasks in two different orders, from Step 2 to Step 8 for half of the children and in reverse order, Step 8 to Step 2, for the other half. In each Age $x$ Sex group, half the children were randomly chosen for each order.

After the free-play period, the experimenter reentered the playroom, greeted the child, and carried out the best story condition: He asked the child to act out the best story that he or she could but provided no additional cues or modeling. The story was later scored for the step in the developmental sequence that it demonstrated, in the same manner that the assessment and free-play stories were scored.

\section{Scoring and Interobserver Reliability}

Two undergraduate psychology students independently scored each child's performance from the videotapes in the same manner as in Experiment 1. Both observers were unaware of the exact ages of the subjects and the rationale for the sequence. The second observer scored 40 children, randomly chosen but including every Age $\times$ Sex group. Scoring was again highly reliable. The interrater correlation for highest step passed in the elicited assessment was high $(r=.97)$. For all steps demonstrated, the two observers agreed completely $98 \%$ of the time.

The second observer also scored the occurrence of the six steps in the free-play and best story conditions, but she did not separate the scores for the two conditions. Reliability can therefore be assessed only for the combination of these two conditions. For highest step reached, the interrater correlation was high $(r=.93)$. For all steps demonstrated, the observers showed complete agreement $98 \%$ of the time.

\section{Results}

The results strongly supported the hypothesized sequence, and there was a sharp change in the relation between the steps shown in the several conditions, beginning at Step 5 .

\section{Sequence}

In the elicited-assessment condition, 65 of 68 children fit the sequence perfectly, as shown in Table 3; the other three all skipped Step 6, but for most children Step 6 did fit the sequence. The index of consistency was .89 , indicating a highly scalable sequence.

For the free-play condition, the sequence once again did not prove to be scalable 
Table 3

Distribution of Children Showing Task Profiles in Experiment 2

\begin{tabular}{|c|c|c|c|c|c|c|c|c|}
\hline \multirow{2}{*}{$\begin{array}{l}\text { Developmental } \\
\text { step of profiles }\end{array}$} & \multicolumn{6}{|c|}{ Role-playing task } & \multirow[b]{2}{*}{$n$} & \multirow[b]{2}{*}{$M$ age } \\
\hline & 2 & 4 & 5 & 6 & 7 & 8 & & \\
\hline 0 & - & - & - & - & - & - & 2 & 1 year 6 months \\
\hline 2 & + & - & - & - & - & - & 8 & 2 years 7 months \\
\hline 4 & + & + & - & - & - & - & 23 & 4 years \\
\hline 5 & + & + & + & - & - & - & 11 & 4 years 7 months \\
\hline 6 & + & + & + & + & - & - & 9 & 5 years 3 months \\
\hline 7 & + & + & + & + & + & - & 3 & 6 years \\
\hline 8 & + & + & + & + & + & + & 9 & 6 years 3 months \\
\hline \multirow[t]{2}{*}{ Nonscalable profiles } & + & + & + & - & + & - & 2 & 6 years \\
\hline & + & + & + & - & + & + & 1 & 7 years 6 months \\
\hline Total & & & & & & & 68 & \\
\hline
\end{tabular}

Note. Occurrence of the designated type of role playing is indicated by + .

$(I=.38)$. Of the 68 children, only $53 \mathrm{fit}$ the predicted Guttman-scale profiles. The omission of steps did not consistently occur in the order of their acquisition, and thus there was no evidence for a sequence combining acquisition and omission.

\section{Highest Step}

When the dependent variable was highest step in a given condition, an analysis of variance showed the expected Age $\times$ Condition interaction. Age, sex, and order of tasks were between-subjects variables; condition (assessment, free play, best story) was a within-subjects variable; and the

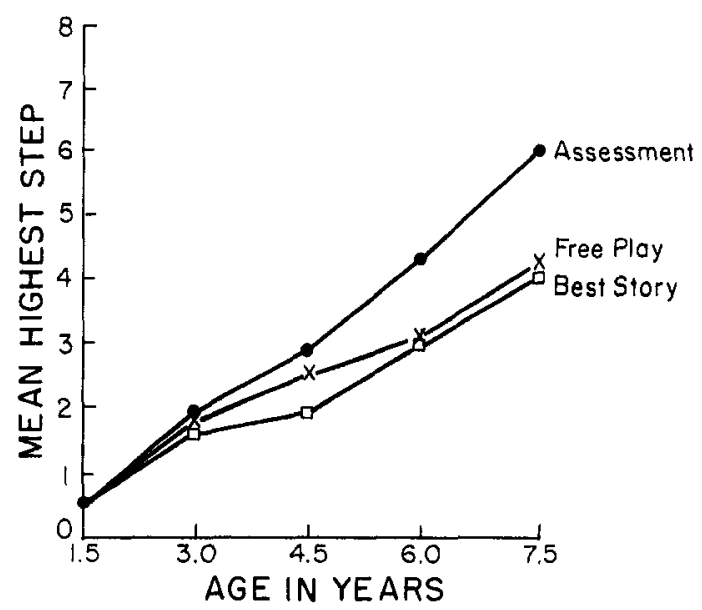

Figure 1. Mean highest step as a function of condition and age in Experiment 2. steps were treated as a 6-point scale. Only the middle three age groups were used in analysis of variance because the youngest and oldest groups included only four children each. As shown in Figure 1, there was an age effect, $F(2,48)=14.27, p<.001$, a condition effect, $F(2,96)=16.75, p<$ .001 , and an Age $\times$ Condition interaction, $F(4,96)=3.20, p<.05$, but no other significant effects. With age, the difference between the assessment condition and the other two conditions increased. The results for the $1 \frac{1}{2}$ - and $71 / 2$-year-olds fit the same pattern (see Figure 1).

The Newman-Kuels multiple range test indicated that there were no significant differences between the conditions at age 3 years and that the elicited-assessment condition was generally higher than the other two. The following paired comparisons between conditions were significant: For the $4 \frac{1}{2}-$ year-olds, the mean highest step in the assessment condition was higher than that in the best story condition $(p<.01)$. For the 6-year-olds, the mean highest step in the assessment condition was higher than that in both the free-play and the best story conditions $(p<.001)$. No other condition differences within age groups were significant. Across age groups within each condition, all paired comparisons were significant at the .05 level or better except for that between 3 - and $4 \frac{1}{2} 2$-year-olds in the best story condition and that between 41/2- and 6-yearolds in the free-play condition. 
The Age $\times$ Condition interaction can also be analyzed in terms of developmental step rather than age. If the interaction is a result of a change in developmental level, then according to skill theory the differences between conditions should first become evident at Step 5, the first step at the level of representational mappings. Figure 2 shows that the difference between the assessment and free-play conditions first emerges at Step 5 in both experiments: The proportion of children playing at their highest assessed step fell precipitously at Step 5 and continued to fall further at higher steps.

The correlations between age and highest step for each of the three conditions were all high (all $p s<.001$ ): Age correlated .76, .63 , and .52 with assessment, free play, and best story, respectively; assessment .75 and .71 with free play and best story, respectively; and free play correlated .84 with best story. Even with age partialed out, the correlations among the conditions remained high (all $p s<.001$ ): Assessment correlated .56 with both free play and best story, and free play correlated .78 with best story.

\section{Discussion}

The results seem to have implications for two separate but related issues, the sequence of social-role development and the reflections of that sequence in spontaneous behavior.

\section{Development of Social Roles}

The present results confirm the hypothesis that in the early preschool years children can understand that people are independent agents and can begin to understand social roles. By $1 \frac{1}{2}$ years of age, most middleclass children can pretend that they are carrying out some action; in this way, they show an understanding that they themselves are agents. By age 2, they can make a doll do something, as if it were acting on its own, thus demonstrating an elementary skill for representing other people as independent agents. Most 3-year-olds can make a doll carry out several activities relating to a role and so show a behavioral role. Most 4-year-

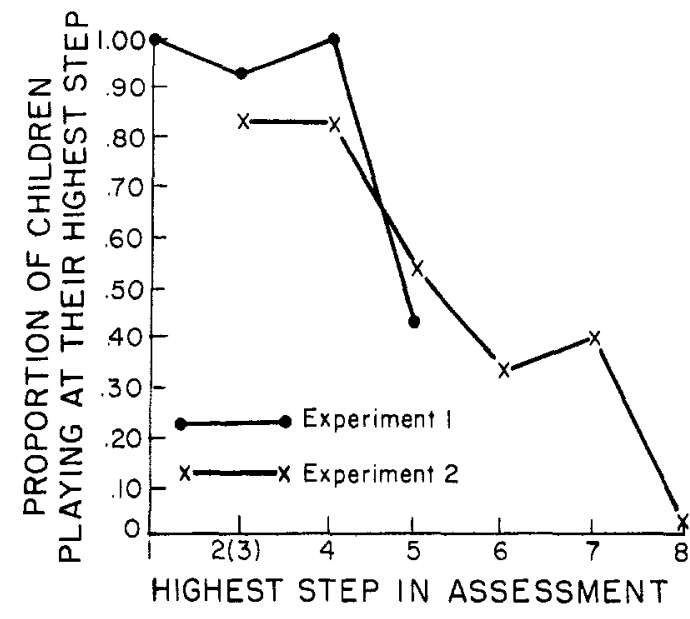

Figure 2. Relation between highest step in assessment and the proportion of children showing that step in play.

olds can act out a social role, relating one behavioral role such as doctor to a complementary role such as patient. Development in the late preschool years involves more complicated combinations of roles, culminating in the ability of most 6-yearolds to have one agent carry out several roles simultaneously.

In the elicited assessment, the children clearly demonstrated the predicted eightstep developmental sequence, described in Table 1. Of 108 children tested, 103 fit the sequence perfectly, and the other 5 skipped only one step. These results provide especially strong support for the sequence because, contrary to previous studies, we assessed each step with an independent task.

Previous research generally supports the broad outline of the sequence of social-role development and thus lends some generality to it. Similar sequences occur across many roles and tasks (e.g., Chambers \& Tavuchis, 1976; Emmerich, 1959, 1961; Greenfield \& Childs, 1977; Piaget, 1928; Sigel et al., 1967). However, some of the specific steps as operationally defined in the sequence and the ages at which steps occur will vary as a function of many task and content differences.

This developmental sequence is consistent with recent research showing that prespec- 
tive-taking abilities begin to emerge long before 6 or 7 years of age. Indeed, the socialrole sequence can be viewed as a measure of a type of perspective taking. Rubin and Pepler (in press) have suggested that one way of making sense of the many apparently contradictory studies on perspective taking is to attempt to describe the sequence in which perspective taking develops from an early age. The social-role sequence seems to provide one starting point for such a description. Early on, children take the perspective of a single agent carrying out individual actions, then they take the perspective of an agent carrying out a behavioral role, then the perspective of an agent filling a social role, and finally the perspective of a more individualized agent filling several social roles at once.

Whether the sequence is conceptualized in terms of perspective taking or only in terms of agents and social roles, it describes how the preschool child gradually constructs skills for one type of social interaction. Step by step, children build more complex skills until age 6 or 7 they have the ability to deal with some of the complexities of interactions involving social roles.

These increases in complexity need to be analyzed in terms of the child's skills, not just in terms of simple changes in the stimulus complexity of the stories or simple, linear, cumulative increases in ability. For example, the number of dolls increased generally across the stories, but this increase cannot explain the sequence, since for many adjacent steps there was no increase, and in one case there was actually a reversal: The number of dolls used for the steps was $0,1,1,2,2,3,2$, and 3 , respectively. Similarly, the length of the stories did not progress consistently from shortest to longest; the length of time required to model a story varied from only 30 to $50 \mathrm{sec}$, and the length did not increase systematically from step to step. The verbal abilities required to act out a story likewise increased across the sequence, but the structures of the behaviors and verbalizations, not simply the amount, determined which steps a child passed. Thus, although all these factors undoubtedly influenced overall performance, they could not account in any simple way for the invariant sequentiality of the steps.

\section{Relation of Elicited Assessment to Spontaneous Behavior}

The free-play and best story conditions were included to provide measures of the relation between the highly structured, elicited-imitation assessment and more spontaneous behaviors. The data indicate that a striking developmental shift occurred in this relation. Beginning with Step 5, the first step at the cognitive level of representational mappings, half or more of the children did not play at their highest step (see Figure 2) or show that step in the best story condition. The steps shown in the free-play and best story conditions did continue to increase with age, but at a lower rate than the steps shown in the assessment condition (see Figure 1).

The use of modeling prior to the free-play condition allowed us to test a hypothesis derived from previous studies that employed the same type of procedure - that children would show an acquisition and omission sequence (Harnick, 1978; Watson \& Fischer, 1977). This hypothesis received no support in either experiment. In addition, behavior under the free-play condition did not show Guttman scales.

Further research will be required to determine the meaning of the developmental shift in highest step shown in the spontaneous conditions, but methodological problems will not easily account for it. Step 5, where the shift began, involves a type of story that is often seen in children's play - a doctor examining a patient. Also, Steps 5 and/or 6 occurred in the play and best stories of most children whose highest step in the assessment was 6,7 , or 8 , and Steps 7 and 8 occurred in the play and best stories of some children.

To check the possibility that the scoring criteria for the highest steps were somehow responsible for the shift, the first author rescored the videotapes of the nine children who showed the largest differences - two or more steps-between assessment and free play. This rescoring was an open-ended 
search for any activity that could possibly be interpreted as a role intersection or other form of representational system. None of the children acted out a story that could be identified as involving a representational system of any kind.

The pattern of the data also seems to preclude an explanation of the results in terms of statistical artifact. Suppose that the children had some upper limit on the number of steps that they would show in play; in that case, the proportion of children demonstrating a step in play would decrease as more steps were available to the child, so that the proportion of children playing at their highest step would fall gradually across the entire sequence, not abruptly at Step 5 .

If the developmental shift cannot be explained away, then what could it mean? One possibility is that children at this point undergo some sort of motivational shift such that they are no longer motivated to perform at the highest step that they are capable of. Another related possibility is that the shift reflects an emerging separation of imitative and spontaneous abilities.

Whatever the proper explanation of the developmental shift, the finding does suggest a different orientation to the question of the validity of imitation as a tool for assessing cognitive development. Instead of asking whether imitation is a good general assessment tool, perhaps it would be more productive to ask how measures based on direct imitation relate to other measures of development, especially those involving more spontaneous behavior. For example, the developmental shift would seem to imply that imitation provides a good measure of a child's capacities in the early preschool years. Beginning at about age 4 , however, imitation may systematically overestimate a child's spontaneous preferences. Or stated the opposite way, spontaneous behavior may underestimate capacities of imitation.

Indeed, this orientation can be applied beyond the realm of imitation. Rigorous methods like the elicited-assessment procedure provide not only strong tests of developmental sequences but also the possibility of relating those sequences to spontaneous behavior. The developmental sequence of social roles that we have tested should apply to most concrete roles that children experience commonly in their daily lives, roles like mother and father, boy and girl, teacher and pupil. This sequence, measured in various role domains, will provide measures that can be used with some precision to investigate the relation between role concepts and competence in spontaneous social interactions involving the same roles. In this way, perhaps researchers can begin to understand more fully how cognitive-developmental change relates to the child's normal behavior in everyday life.

\section{References}

Bigner, J. J. Second borns' discrimination of sibling role concepts. Developmental Psychology, 1974, 10, 564-673.

Bloom, L., Rocissano, L., \& Hood, L. Adult-child discourse: Developmental interaction between information processing and linguistic knowledge. Cognitive Psychology, 1976, 8, 521-522.

Chambers, J. C., \& Tavuchis, N. Kids and kin: Children's understanding of American kin terms. Journal of Child Language, 1976, 3, 63-80.

Dasen, P., Inhelder, B., Lavallée, M., \& Retschitzki, J. Naissance de l'intelligence chez l'enfant baoulé de Côte d'Ivoire. Berne, Switzerland: Huber, 1978.

Elkind, D. Children's conception of brother and sister: Piaget Replication Study V. Journal of Genetic Psychology, 1962, 100, 129-136.

El'Konin, D. Symbolics and its functions in the play of children. In R. E. Herron \& B. Sutton-Smith (Eds.), Child's play. New York: Wiley, 1971.

Emmerich, W. Young children's discriminations of parent and child roles. Child Development, 1959, 30, 403-419.

Emmerich, W. Family role concepts of children ages six to ten. Child Development, 1961, 32, 609624.

Fischer, K. W. A theory of cognitive development: The control and construction of hierarchies of skills. Psychological Review, in press.

Fischer, K. W., \& Corrigan, R. A skill approach to language development. In R. Stark (Ed,), Language behavior in infancy and early childhood. The Netherlands: Amsterdam, Elsevier North Holland, in press.

Gelman, R. Cognitive development. Annual Review of Psychology, 1978, 29, 297-332.

Gottlieb, S. Modeling effects upon fantasy. In J. L. Singer, The child's world of make-believe: Experimental studies of imaginative play. New York: Academic Press, 1973.

Green, B. F. A method of scalogram analysis using summary statistics. Psychometrika, 1956, 1, 79-88. 
Greenfield, P. M., \& Childs, C. P. Understanding sibling concepts: A developmental study of kin terms in Zinacantan. In P. Dasen (Ed.), Crosscultural Piagetian psychology. New York: Gardner Press, 1977.

Harnick, F. S. The relationship between ability level and task difficulty in producing imitation in infants. Child Development, 1978, 49, 209-212.

Harter, S. A cognitive-developmental approach to children's expression of conflicting feelings and a technique to facilitate such expression in play therapy. Journal of Consulting and Clinical Psychology, 1977, 45, 417-432.

McCall, R. B., Parke, R. D., \& Kavanaugh, R. D. Imitation of live and televised models in children one to three years of age. Monographs of the Society for Research in Child Development, 1977, 42 (5, Serial No. 173).

Mead, G. H. Mind, self, and society. Chicago: University of Chicago Press, 1934.

Piaget, J. Judgment and reasoning in the child (M. Warden, trans.). London: Routledge \& Kegan Paul, 1928.

Piaget, J. Play, dreams and imitation in childhood
(C. Gattegno \& F. M. Hodgson, trans.). New York: Norton, 1951.

Rubin, K. H., \& Pepler, D. J. The relationship of child's play to social-cognitive growth and development. In H. Foot, T. Chapman, \& J. Smith (Eds.), Friendship and childhood relationships. London: Wiley, in press.

Scollon, R. Conversations with a one year old. Honolulu: University Press of Hawaii, 1976.

Sigel, I. E., Saltz, E., \& Roskind, W. Variables determining concept conservation in children. Journal of Experimental Psychology, 1967, 74, 471-475.

Slobin, D. I., \& Welsh, C. A. Elicited imitation as a research tool in developmental psycholinguistics. In C. A. Ferguson \& D. I. Slobin (Eds.), Studies of child language development. New York: Holt, Rinehart \& Winston, 1973.

Watson, M. W., \& Fischer, K. W. A developmental sequence of agent use in late infancy. Child Development, $1977,48,828-836$.

Received February 2, 1980 